\title{
IONOSPHERIC DISTURBANCES OVER EASTERN SIBERIA DURING APRIL 12-15, 2016 GEOMAGNETIC STORMS
}

\author{
A.V. Rubtsov \\ Irkutsk State University, \\ Irkutsk,Russia,avrubcov@mail.ru \\ Institute of Solar-Terrestrial Physics SB RAS, \\ Irkutsk,Russia,avrubcov@mail.ru \\ B.M. Maletckii \\ Irkutsk State University, \\ Irkutsk,Russia,maletskiy@iszf.irk.ru \\ Institute of Solar-Terrestrial Physics SB RAS, \\ Irkutsk,Russia,maletskiy@iszf.irk.ru \\ E.I. Danilchuk \\ Irkutsk State University,
}

\author{
Irkutsk,Russia,danilchuk.k@mail.ru \\ E.E. Smotrova \\ Irkutsk State University, \\ Irkutsk, Russia, katerina.smotrova@mail.ru \\ A.D. Shelkov \\ Irkutsk State University, \\ Irkutsk, Russia,ekzereal@gmail.com
A.S. Yasyukevich
Institute of Solar-Terrestrial Physics SB RAS,
Irkutsk,Russia,annpol@iszf.irk.ru

\begin{abstract}
We present the results of the complex study of ionospheric parameter variations during two geomagnetic storms, which occurred on April 12-15, 2016. The study is based on data from a set of radiophysical and optical instruments. Both the storms with no sudden commencement were generated by high-speed streams from a coronal hole. Despite the minor intensity of the storms (Dst $\geq-55$ and $-59 \mathrm{nT}$ ), we have revealed a distinct ionospheric response to these disturbances. A negative response of electron density and F2-layer critical frequency was observed during the main phase of both the storms. The amplitude of the negative response was higher for the second storm. The period of negative electron density deviations was accompanied by an increase in the peak height, as well as by the downward plasma drift in the
\end{abstract}

evening and night hours, which is not typical of quiet conditions. We have also recorded sharp peaks in the AATR (Along Arc TEC Rate) index and in total electron content noise spikes on average $2-2.5$ times. This indicates an intensification of small-scale ionospheric disturbances caused by disturbed geomagnetic conditions and high substorm activity.

Keywords: ionosphere, GNSS, incoherent scatter radar, geomagnetic storms, ionospheric disturbances.

\section{INTRODUCTION}

Earth's ionosphere is a complex dynamic medium whose state is determined by many different factors. Among the most powerful disturbing phenomena having a significant effect on ionospheric plasma dynamics are geomagnetic storms associated with solar activity and abrupt changes in solar wind (SW) and interplanetary magnetic field (IMF) parameters [Bryunelli, Namgaladze, 1988; Danilov, 2013]. Geoeffective sources producing strong magnetic storms are coronal mass ejections (CME) and corotating interaction regions (CIR) and related high-speed streams from coronal holes [Yermolaev, Yermolaev, 2006].

The response of Earth's upper atmosphere to geomagnetic disturbances is a complex variety of phenomena such as changes in the neutral composition of the thermosphere $\left(\mathrm{O} / \mathrm{N}_{2}\right.$ density ratio) and in the ionospheric wind circulation system, generation of large-scale traveling ionospheric disturbances, precipitation of high-energy particles in the auroral region, penetration of magnetospheric currents, etc. [Buonsanto, 1999; Mendillo, 2006; Afraimovich et al., 2008; Astafyeva et al., 2016]. These factors have a strong impact on the electron density in the ionosphere, which in turn may lead to serious disturbances in various radionavigation systems using the ionospheric radiopath [Blagoveshchenskii, 2013; Demyanov, Yasukevich, 2014; Kotova et al., 2017]. Much research is therefore devoted to ionospheric manifestations of geomagnetic disturbances.

It has been noted that the ionospheric response to a magnetic disturbance at a particular point may depend on local time, season [Fuller-Rowell et al., 1996], as well as on geographic and geomagnetic coordinates. For the midlatitude ionosphere, a typical storm has a positive initial phase, which then gives way to a longer and more intense negative disturbance called the storm main phase. It has been shown that in the mid-latitude ionosphere in summer there is often a negative response to geomagnetic disturbances, whereas in winter there is most likely a positive response, especially in the daytime [Wrenn et al., 1987; Buonsanto, 1999; Kurkin et al., 2004]. Seasonal and diurnal variations in ionospheric effects of geomagnetic storms are attributed to the thermospheric wind asymmetry and intradiurnal differences in the current system response to geomagnetic disturbances (DC/AC effect) [Wrenn et al., 1987; Rodger et al., 1989]. Recent research has revealed the presence of intense positive disturbances of electron density, which occur in the daytime on the third to fifth day after the onset of the recovery phase of geomagnetic storms [Ratovsky et al., 2018; Klimenko et al., 2018]. The 
authors called these pheno-mena the after-effect of geomagnetic storms.

Each geomagnetic storm is a unique phenomenon with different characteristics. Therefore, taking into account the complexity and comprehensiveness of ionospheric manifestations of geomagnetic storms, a multiinstrumental approach is more and more widely used to study these phenomena [Afraimovich et al., 2002; Crowley et al., 2006; Balan et al., 2011; Astafyeva et al., 2015, 2017]. The application of a large set of different instruments (ground-based and satellite, radiophysical, optical, etc.) allows us to trace the entire chain of phenomena occurring in the upper atmosphere during these events. Of particular interest here are studies of ionospheric disturbances both on a global scale [Afraimovich et al., 2013; Astafyeva et al., 2014, 2017; Klimenko et al., 2017 and references therein] and in individual regions.

Eastern Siberia is characterized by a significant shift between geographic and geomagnetic coordinates defining respectively the distribution of the neutral atmosphere parameters and the configuration of ionospheric currents and electromagnetic plasma drift. This stimulates the interest in studying ionospheric effects of geomagnetic storms for individual major isolated events [Kurkin et al., 2001; Leonovich et al., 2013; Polekh et al., 2017] and a comparative analysis of storms of different intensity [Romanova et al., 2013; Zolotukhina et al., 2018; Kurkin et al., 2018].

In this paper, we carry out a comparative analysis of ionospheric disturbances in Eastern Siberia during two consecutive geomagnetic storms, which occurred on April 12-15, 2016 in the decline phase of solar cycle 24 . This analysis relies on data on total electron content (TEC) variations obtained from ground-based dual-frequency receivers of signals from global navigation satellite systems (GNSS), DPS4 ionosonde data, Irkutsk incoherent scatter radar (IISR) data, and optical measurements of a wide-angle highly sensitive camera. This set of instruments enabled a comprehensive study of ionospheric effects of these storms. Section 1 presents parameters of SW and geomagnetic indices. Section 2 performs a comparative analysis of the observed ionospheric disturbances. Section 3 reports the results of observations of storm effects in the optical range. The last section draws a conclusion and discusses the results.

\section{GEOMAGNETIC ACTIVITY AND SOLAR WIND}

The period of interest corresponds to the decline phase of solar cycle 24 . Solar minimum is generally characterized by moderate and minor $(D s t \geq-100 \mathrm{nT})$ recurrent magnetic storms whose sources are associated with high-speed streams from coronal holes (CIR storms) [Burlaga, Lepping, 1977]. Such storms exhibit a gradual development, therefore they have no sudden storm commencement (SSC) [Loewe, Prölss, 1997].

The April 12-15, 2016 period showed a higher geomagnetic activity level. During this period there were two consecutive CIR storms whose main phase began at 20:30 UT on April 12 and at 9:40 UT on April 14 respectively (Figure 1). Even before the first storm, there were geomagnetic variations $(S Y M-H \geq-20 \mathrm{nT}$, Figure 1 , $e)$. The $A E$ index showed increasing substorm activity from 10:00 UT on April 12 (Figure 1, $d$ ) and exceeded $1000 \mathrm{nT}$ by $\sim 18: 40 \mathrm{UT}$. The IMF $B_{\mathrm{z}}$ component was predominantly southward, with strong oscillations observed (Figure $1, a$ ). The SW velocity $V_{\mathrm{SW}}$ from $\sim 13: 30$ UT on April 12 before the beginning of the main phase of the first storm was $\sim 400 \mathrm{~km} / \mathrm{s}$ (Figure $1, b$ ). At the same time, the SW density $n_{\mathrm{SW}}$ increased to $52 \mathrm{~cm}^{-3}$ at 19:00 UT (Figure 1,c).

The beginning of the main phase of the first geomagnetic storm was characterized by a sharp change in the direction of IMF $B_{z}$ to southward and a decrease in $n_{\mathrm{SW}}$ at 20:30 UT on April 12 (see Figure 1, $a$ ). Simultaneously, $V_{\text {SW }}$ increased to $\sim 470 \mathrm{~km} / \mathrm{s}$ (Figure $1, b$ ), then $V_{\mathrm{SW}}$ continued to gradually increase, whereas $n_{\mathrm{SW}}$ dropped to a quasi-stable value of $\sim 9 \mathrm{~cm}^{-3}$. The $A E$ index also increased rapidly (Figure $1, d$ ), the $S Y M-H$ index began to decrease (Figure 1,e). During the main phase of the first storm, which lasted about 8 hours, IMF $B_{z}$ exhibited frequent abrupt changes but remained largely negative. These abrupt changes were accompanied by positive jumps of $V_{\mathrm{SW}}$ and $A E$, thus generating substorms. $A E$ reached a maximum of $1327 \mathrm{nT}$ at $\sim 00: 55 \mathrm{UT}$ on April 13 , and $S Y M-H$ fell to $-70 \mathrm{nT}$. At the same time, $n_{\mathrm{SW}}$ sharply decreased to $\sim 5 \mathrm{~cm}^{-3}$. The storm main phase ended at $\sim 4: 45$ UT when $S Y M-H$ again reached a minimum of $-70 \mathrm{nT}(D s t=-55 \mathrm{nT})$ (Figure $1, e)$.

Figure $1, e$ shows that the recovery phase of the first storm is clearly divided into two stages: with rapid ( 04:45-10:10 UT on April 13) and slow ( 10:10 UT on April 13, 07:40 UT on April 14) SYM- $H$ changes. Following [Zolotukhina et al., 2018], we will call the period of rapid change of $S Y M-H$ in the recovery phase the early recovery phase; and that of slow change, the late recovery phase.

During the early recovery phase, until $\sim 10: 10$ UT on April 13 , IMF $B_{z}$ was $\sim 0 \mathrm{nT}$, and $V_{\mathrm{SW}}$ reached its maximum of $650 \mathrm{~km} / \mathrm{s}$ at $~ 8: 00$ UT (Figure $1, b$ ). The late recovery phase of the first storm may be considered in the context of the forthcoming second storm. Note that the behavior of IMF $B_{z}$ before the second storm was more quiet than before the first one. Minimum substorm activity occurred during the same period, as derived from $A E$ data. At $\sim 7: 40 \mathrm{UT}, V_{\mathrm{SW}}$ increased abruptly from $\sim 450$ to $\sim 490 \mathrm{~km} / \mathrm{s}$ (Figure $1, b$ ); and $n_{\mathrm{SW}}$, from $\sim 3$ to $\sim 7 \mathrm{~cm}^{-3}$ (Figure $1, c$ ). Unlike the first storm, $V_{\mathrm{SW}}$ was higher and there was no superdense proton flux.

The main phase of the second storm began at $~ 9: 40$ UT on April 14 with a sudden change in the direction of IMF $B_{z}$ to southward (Figure $1, a$ ) and an increase in $V_{\text {SW }}$ from $\sim 470$ to $\sim 500 \mathrm{~km} / \mathrm{s}$ (Figure 1, b). As the main phase of the second storm developed, substorm activity increased rapidly, as derived from $A E$ data. $A E$ reached a maximum of $1261 \mathrm{nT}$ at $\sim 12: 35 \mathrm{UT}$ on April 14; at that time $S Y M-H$ decreased by $10 \mathrm{nT}$ (Figure 1 , d). $S Y M-H$ reached a minimum of $-68 \mathrm{nT}(D s t=-59 \mathrm{nT})$ at 20:30 UT on April 14 (Figure 1,e). Thus, the main phase of the second storm lasted by $\sim 3$ hours longer than that of the first one. In the recovery phase of the second storm, $S Y M-H$ gradually 


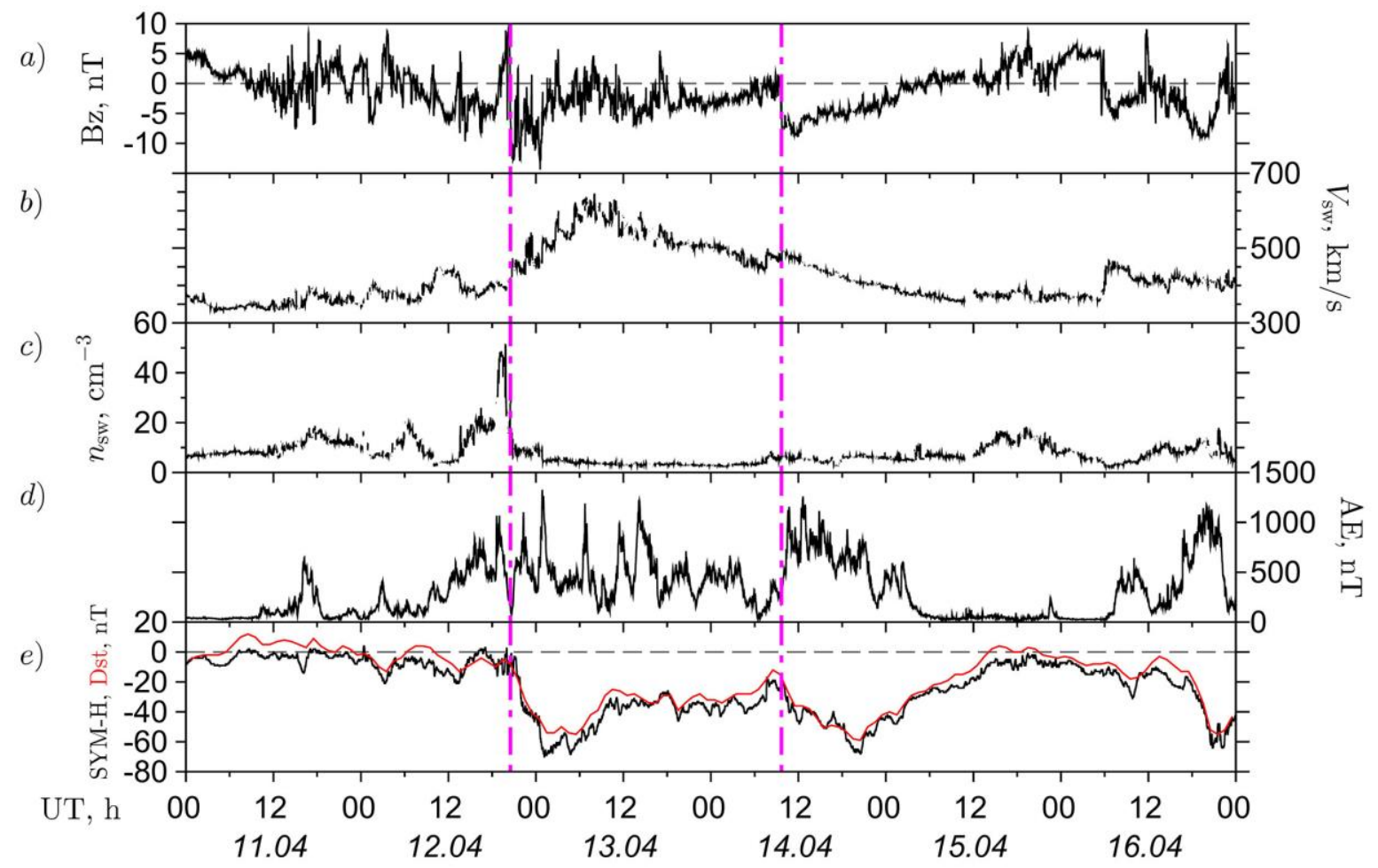

Figure 1. Interplanetary and geomagnetic conditions in the April 11-16, 2016 period: IMF $B_{\mathrm{Z}}(a)$; solar wind velocity $V \mathrm{sw}(b)$, solar wind density $n_{\mathrm{Sw}}(c), A E$ index $(d), S Y M-H$ (black line) and $D s t$ (red line) indices $(e)$. Vertical dash-dot lines indicate the time of the onset of storm main phases

increased to 15:00 UT on April 15. A slight increase in substorm activity during the recovery phase of the second storm occurred from $\sim 00: 50$ to $\sim 2: 25$ UT on April 15, then $A E$ returned to the quiet level. The entire recovery phase of the second storm lasted for $\sim 18.5$ hours, whereas that of the first storm did not end owing to the onset of the second storm.

Storms driven by CIR and/or subsequent high-speed streams typically recur every 27 days. For the April $12-15$, 2016 storm, the recurrence took place on May 8-11, 2016 when the strongest geomagnetic storm of 2016 occurred (the main disturbance on May 8). Thus, these storms are classified as recurrent.

Next, we consider ionospheric disturbances generated by the April 12-15, 2016 geomagnetic storms. To better understand effects during the storms, we compare our results with those for the reference day of April 9, 2016, which is included in the list of the quietest days of the month - CKdays, International Q-days and D-days [http://wdc.kugi.kyoto-u.ac.jp/qddays/index.html].

\section{IONOSPHERIC DISTURBANCES}

The impact of geomagnetic storms and substorms on the mid-latitude ionosphere, which manifests itself as electron density disturbances, has been studied using data from the set of scientific instruments located in Eastern Siberia. Measurements made with the vertical sounding ionosonde DPS-4 [Reinisch et al., 1997], located in Irkutsk $\left(52^{\circ} \mathrm{N} ; 104^{\circ} \mathrm{E}\right)$, provided data on variations in the critical frequency $f_{\mathrm{o}} \mathrm{F} 2$ and $\mathrm{F} 2$ peak height $h_{\mathrm{m}} \mathrm{F} 2$. Ionograms were processed manually [Piggott, Rawer, 1972].
Direct measurements of $N_{\mathrm{e}}$ in an altitude range 150-600 $\mathrm{km}$ and of the vertical plasma drift velocity $v_{\mathrm{z}}$ were made with IISR $\left(53^{\circ} \mathrm{N} ; 103^{\circ} \mathrm{E}\right)$ [Zherebtsov et al., 2002; Potekhin et al., 2009]. Methods for calculating $N_{\mathrm{e}}$ and $v_{\mathrm{z}}$ drift from radar data are described in [Alsatkin et al., 2009; Shcherbakov et al., 2015].

The paper also analyzes data on TEC variations from the dual-frequency GNSS receivers included in the International GNSS Service Network (IGS) [Dow et al., 2009]: IRKJ, IRKM (Irkutsk, $52^{\circ} \mathrm{N} ; 104^{\circ} \mathrm{E}$ ) and BADG (Badary, $51^{\circ} \mathrm{N} ; 102^{\circ} \mathrm{E}$ ).

As a criterion for evaluating the intensity of TEC variations we utilized the Rate of TEC Index (ROTI), which is a dispersion of TEC change rate [Pi et al., 1997]. ROTI series were averaged in a $5 \mathrm{~min}$ range. To account for the dependence of this index on elevation $\theta$ and to reduce all data to quasi-vertical values, we applied function $M(\varepsilon)$ (for more detail, see [Sanz et al., 2013]). This yielded the Along Arc TEC Rate (AATR) [Juan et al., 2018]. The time resolution of AATR corresponds to that of ROTI series.

We used GNSS data to analyze the dynamics of TEC noise spikes. To calculate this parameter from initial TEC series, we removed the trend to eliminate the effects of satellite motion and cut elevation series $\left(\theta \geq 30^{\circ}\right)$. Then we calculated the second TEC derivative, thus eliminating slow variations (seasonal, diurnal, tidal, etc.). As a result, there is only additive white Gaussian noise. The noise outside the $3 \sigma$ threshold is considered to be the noise spikes.

Note that the local time in Irkutsk LT=UT +7 .

Figure 2 shows $f_{\mathrm{o}} \mathrm{F} 2$ and $h_{\mathrm{m}} \mathrm{F} 2$ variations as derived from ionosonde measurements in Irkutsk on April 11-16, 
2016 against the dynamics of these parameters on the reference day. Figure 3 shows altitude-temporal distribu-

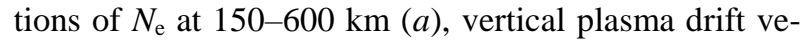
locity variations $v_{\mathrm{z}}$ at $300 \mathrm{~km}$ (black line) and $350 \mathrm{~km}$ (red line) $(b)$, and dynamics of ion $(c)$ and electron $(d)$ temperatures on April 11-15, 2016 from IISR data. The time resolution of $v_{z}$ and temperature is $5 \mathrm{~min}$; of all other parameters, $15 \mathrm{~min}$.

During the period of high substorm activity on April 12 , we observed an increase in $f_{\mathrm{o}} \mathrm{F} 2$ as compared to values on the reference day (Figure 2,a), which was $>1 \mathrm{MHz}$ before the main phase of the first storms. After the beginning of the main phase and within 24 hours on April 13 there was a decrease in $f_{\mathrm{o}} \mathrm{F} 2$, followed by a slight increase in $h_{\mathrm{m}} \mathrm{F} 2$ (by $\sim 20 \mathrm{~km}$ ). In the altitude-temporal distributions of $N_{\mathrm{e}}$ according to the IISR data, on April 13 there was also a pronounced decrease in $N_{\mathrm{e}}$ by $(1 \div 2) 10^{5} \mathrm{~cm}^{-3}$ (Figure $3, a$ ). In this case, the behavior of the vertical plasma drift differed from the quiet diurnal variation. From 20:00 UT, ionospheric plasma rapidly drifted downward with a velocity up to $35 \mathrm{~m} / \mathrm{s}$ at $300 \mathrm{~km}$ and with a velocity up to $25 \mathrm{~m} / \mathrm{s}$ at $350 \mathrm{~km}$ (two times faster than under quiet conditions). This downward plasma drift was observed until $\sim 00: 00$ UT (Figure $3, b$ ). Note that from 10:00 UT on April 13 to 01:00 UT on April 14, ionograms showed the F-spread effect (Figure 4, $a$ ) indicating the presence of large-scale ionospheric irregularities.

The most significant amplitude ionospheric variations were recorded during the onset of the main phase of the second storm. Figure 2 shows that after 09:40 UT there was a stepwise increase in $f_{\mathrm{o}} \mathrm{F} 2$ by $\sim 3 \mathrm{MHz}$ relative to the quiet level. As derived from radar data, the increase in $N$ e was observed from 200 to $400 \mathrm{~km}$, the maximum $N_{\mathrm{e}}$ at $300 \mathrm{~km}$ was $9.2 \cdot 10^{5} \mathrm{~cm}^{-3}$, exceeding that for the reference day by 1.5 times (Figure $3, a$ ). At the same time, there was a positive jump in the plasma drift velocity.

With further development of the storm from 16:45 $\mathrm{UT}$, the positive disturbance of $f_{\mathrm{o}} \mathrm{F} 2$ became negative, and from $\sim 20: 00 \mathrm{UT}$ after the minimum of $f_{\mathrm{o}} \mathrm{F} 2 \approx 2.2 \mathrm{MHz}$ reflections disappeared on ionograms, i.e. an intense absorption (blackout) began. The $f_{\mathrm{o}} \mathrm{F} 2$ and $N_{\mathrm{e}}$ values significantly lower than those on the quiet day were observed throughout the recovery phase of the April 15 storm, whereas the near-noon maximum disappeared in the diurnal variation of $N_{\mathrm{e}}$ (Figure 2,a). The $f_{\mathrm{o}} \mathrm{F} 2$ values were also low on April 16. The intensity of the negative ionospheric response was higher than that for the first storm, up to $2 \mathrm{MHz}$ in $f_{\mathrm{o}} \mathrm{F} 2$. The $f_{\mathrm{o}} \mathrm{F} 2$ negative disturbance occurred with an increase in $h_{\mathrm{m}} \mathrm{F} 2$ to $+55 \mathrm{~km}$ relative to the reference day (Figure $2, b$ ). Note also that in the evening and night hours on April 14-15, plasma drift velocities were predominantly negative (Figure $3, b$ ), and the modulus $v_{z}$ reached $\sim 32 \mathrm{~m} / \mathrm{s}$, which is not typical of quiet conditions [Altadill et al., 2007]

Ion $T_{\mathrm{i}}$ and electron $T_{\mathrm{e}}$ temperatures (Figure $3, c, d$ ) at different heights were obtained from IISR data, using the technique described in [Tashlykov et al., 2018]. $T_{\mathrm{e}}$ hardly deviated from its quiet diurnal variation during the April 12-15, 2016 geomagnetic storms (Figure 3, d). For ions, a temperature rose during the recovery phase of the storms on April 13 and 15 (Figure 3,c). For the second storm, the positive deviation is more pronounced (up to $200 \mathrm{~K}$ between $\sim 00: 00$ and 15:00 UT on April 15 relative to the quiet day on April 11).

Variations in the spatial averaged AATR for IRKJ, IRKM, and BADG reflect variations in the intensity of small-scale ionospheric irregularities in this region. Before the onset of the first storm, AATR was at the level of the reference day. It started increasing during the main phase of the first storm on April 13, and at $\sim 4: 45$ UT (minimum $S Y M-H$ ) there was a sharp jump in AATR (Figure $4, b)$. Then, several other AATR increases were observed. During the second storm, the jumps were recorded at the beginning of the main phase $(\sim 10: 00 \mathrm{UT}$ on April 14) and after maximum $N_{\mathrm{e}}$ (Figure 3, a) from $\sim 12: 00$ to 14:00 UT. The quieter behavior of the second

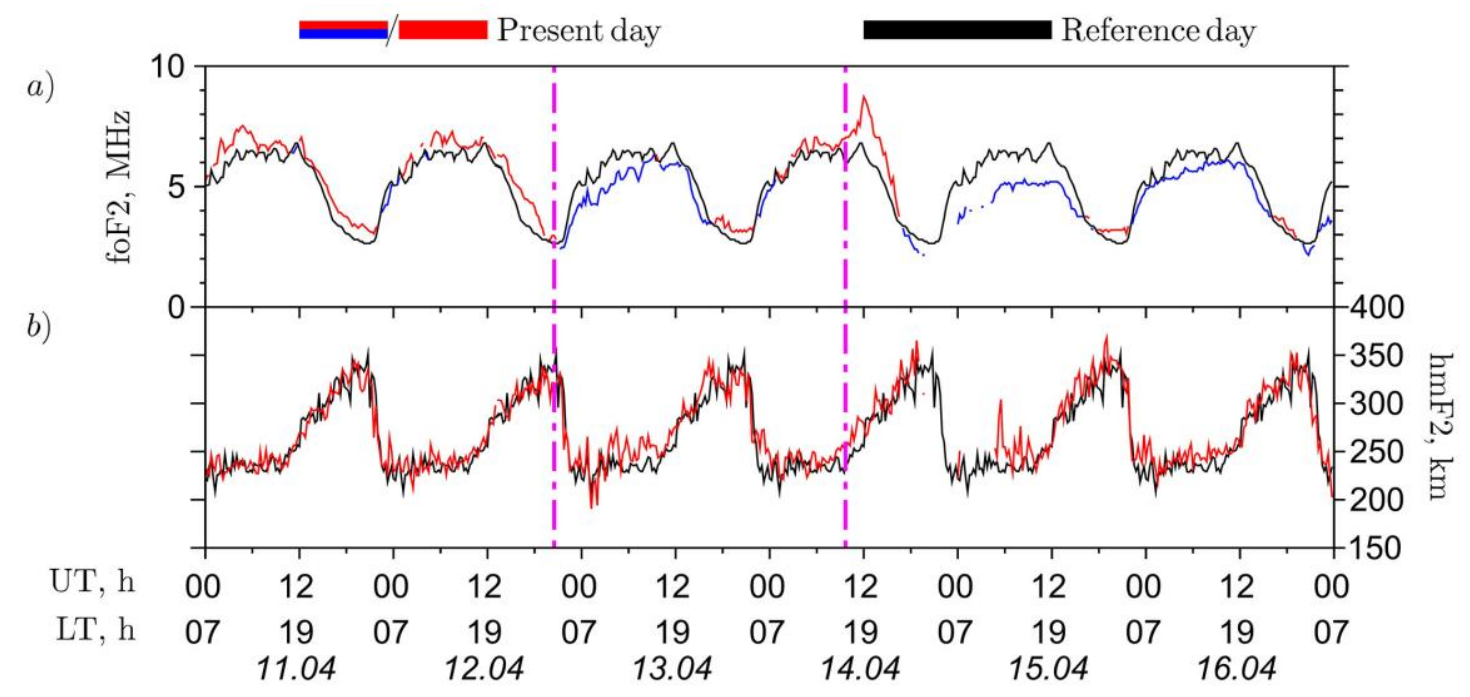

Figure2. Variations in F2-layer parameters on April 11-16, 2016: the critical frequency $f_{\mathrm{o}} \mathrm{F} 2$ higher (red line) and lower (blue line) than values on the reference day (black line) $(a)$; the $\mathrm{F} 2$ peak height $h_{\mathrm{m}} \mathrm{F} 2$ (red line) and values on the reference day (black line) $(b)$ 

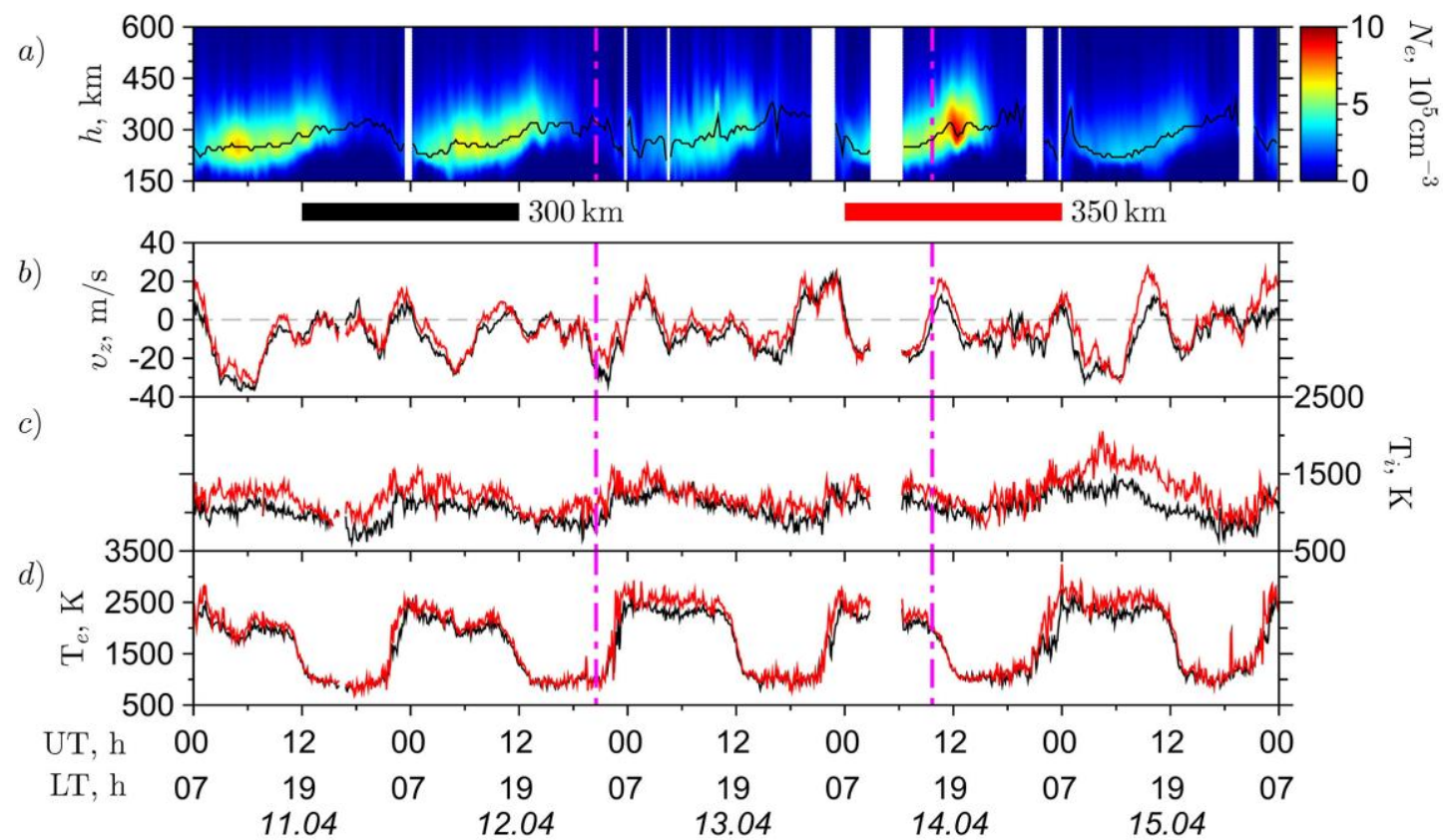

Figure 3. Variations of ionospheric parameters on April 11-15, 2016, as derived from IISR data: the electron density $N_{\mathrm{e}}$ at $150-600 \mathrm{~km}$ in increments of $10 \mathrm{~km}$ and the height of maximum electron density (black line) (a); vertical plasma drift velocity $v_{z}$ (b); ion temperature $T_{\mathrm{i}}(c)$; electron temperature $T_{\mathrm{e}}$ at $300 \mathrm{~km}$ (black line) and $350 \mathrm{~km}$ (red line) (d)
Irkutsk, IR352
2016.04.13 (104) 13:15:00_L
2016.04.13 (104) 21:30:00_I-

a)

b)
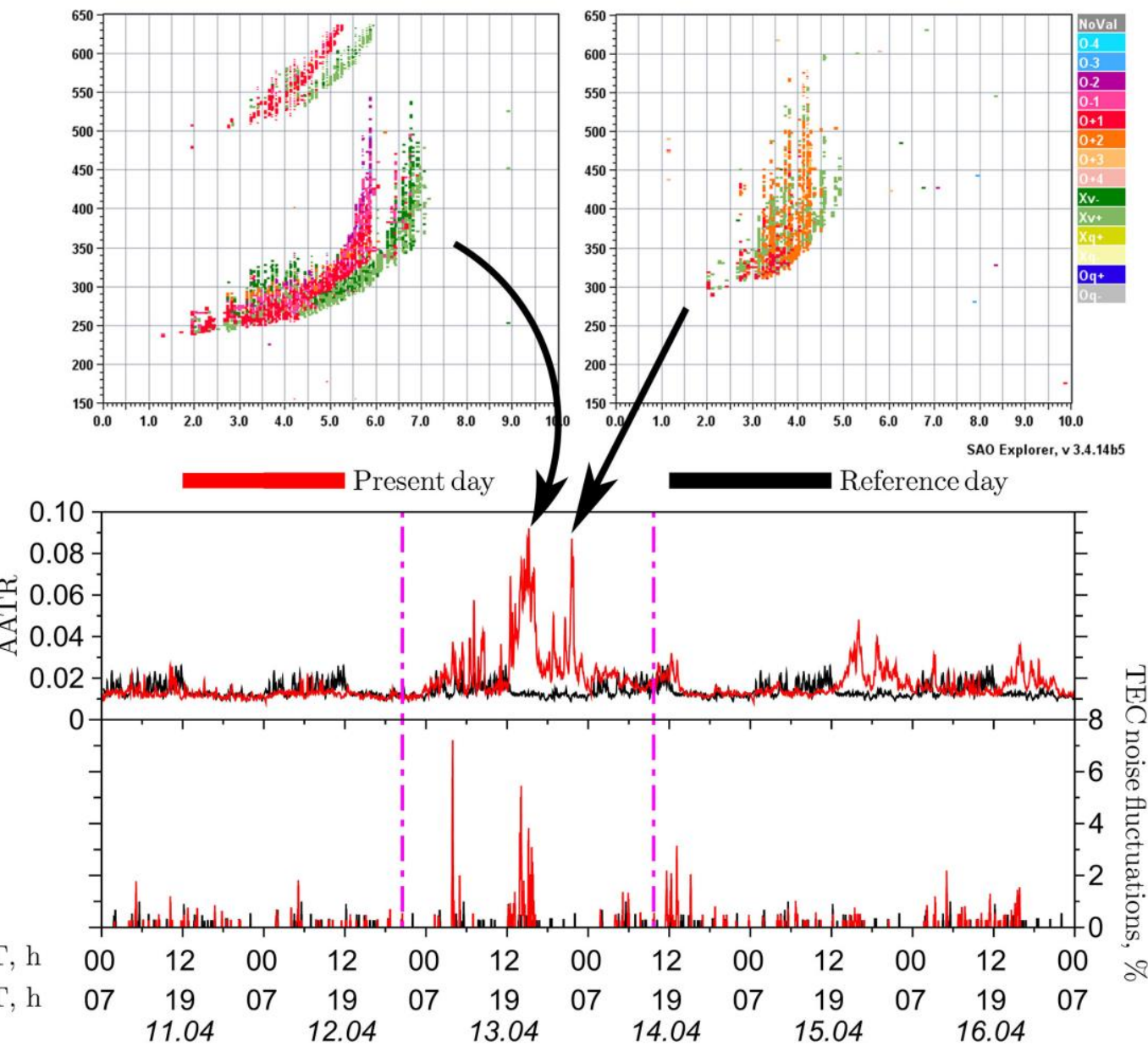

Figure 4. Examples of vertical sounding ionograms with F-spread effect (a) at 13:15 UT (left) and 21:30 UT (right) on April 13. Variations in AATR $(b)$ and TEC noise spikes $(c)$ on April 11-16, 2016 (red line) against the dynamics of these parameters on the reference day (black line) 
storm also manifested itself in the absence of strong fluctuations of $A A T R$ during the recovery phase. In turn, the recovery phase during the first storm stands out as having strong disturbances of $A A T R$ whose values exceed those for the reference day 6-9 times. These disturbances began at 12:00 UT on April 13 and reached extreme values by $\sim 16: 30$ UT, and then started decreasing; during this period $A A T R$ values were about two times higher than those on the reference day (comparable to the disturbances during the main phase). Two more sharp jumps of AATR to extremely high values occurred at 20:30 and $\sim 21: 30$ UT. The constant excess over the level of the reference day lasted until 4:00 UT on April 14. This interval is close to the period of F-spread observation on ionograms (Figure 4, $a$ ).

TEC noise spikes indicate the presence of small-scale ionospheric irregularities, which affect the GNSS signal [Demyanov, Yasukevich, 2014; Demyanov et al., 2019]. By analyzing TEC noise data for April 12-15, 2016, averaged at each time point for IRKJ, IRKM, and BADG receivers, and considering their deviations from those for the reference day, we determined moments of the greatest noise spikes (Figure 4, $c$ ). The obtained TEC spikes distribution correlates well with $A A T R$ variations, in particular in the interval of extremely high AATR from $\sim 04: 00$ to $\sim 16: 30$ UT on April 13 in the recovery phase of the first storm (Figure $4, b$ ). Higher noise spikes were also recorded on April 14 during the second storm. Thus, the noise spikes and extremely high AATR indicate the intensification of small-scale ionospheric disturbances caused by disturbed geomagnetic conditions and high substorm activity. The percentage of noise spikes increased, on average, $2-2.5$ times relative to the reference day.

\section{MANIFESTATIONS IN THE OPTICAL RANGE}

Of particular interest is the atmospheric response to geomagnetic disturbances manifesting themselves as airglows. We have studied the dynamics of 557.7 and 630 $\mathrm{nm}$ atomic oxygen emission intensities. Maxima of these emissions in the atmosphere are located at heights of 97 and $270 \mathrm{~km}$ respectively. The most intense emission generally occurs at the $630 \mathrm{~nm}$ wavelength, which also directly depends on Dst [Mikhalev, 2013]. This emission is often regarded as an indicator of changes in $N_{\mathrm{e}}$ and dynamics of the upper atmosphere during mid-latitude airglows. At the same time, there is no consensus about the dependence of the $557.7 \mathrm{~nm}$ emission intensity on the geomagnetic activity level [Leonovich et al., 2012]. As a control parameter we considered the $470 \mathrm{~nm}$ airglow intensity.

The emission intensity was studied using a wide-angle highly sensitive camera FILIN-1C installed in the village of Tory $\left(52^{\circ} \mathrm{N} ; 103^{\circ} \mathrm{E}\right)$ with an exposure of $300 \mathrm{~s}$. In the period of interest on April 12-15, 2016, the camera worked every day from $\sim 13: 00$ to $\sim 21: 00 \mathrm{UT}$, but data to $\sim$ 14:00 UT and after $~ 20: 00$ UT was ignored because of strong influence of sunset/sunrise. Thus, for the study we used data on April 13 (the recovery phase of the first storm) and April 14 (the main phase of the second storm).
Note that in the said period there were dense clouds and a high position of the Moon. These factors have an equal effect on the emission intensity at all wavelengths, therefore they do not hinder the identification of emission intensity variations at one wavelength relative to the other.

To study the emission variations, we calculated the ratio of differences between intensities of the $630 \mathrm{~nm}$ emission and the other two $(557.7$ and $\sim 470 \mathrm{~nm}$ ) to the $630 \mathrm{~nm}$ emission intensity. We found no significant deviations in comparison with the reference day of April 13, although there were some fluctuations in the $630 \mathrm{~nm}$ emission from $~ 17: 00$ to 18:00 UT (Figure 5, a). Disturbances on April 14 began after 18:00 UT, and at 19:30 UT a peak increase in the $630 \mathrm{~nm}$ emission intensity relative to the other two occurred. The $630 \mathrm{~nm}$ emission intensity was high until the end of observations on April 14 (Figure 5, b).

Taking into account that these storms are minor, the 630 $\mathrm{nm}$ emission intensity increase is most likely to be caused by collisions between oxygen atoms and thermal electrons of the ionosphere or dissociative recombination [Tashchilin, Leonovich, 2016].

The low intensity of the storms may also be the reason why we have not recorded the increase in the $557.7 \mathrm{~nm}$ emission intensity, normally observed during strong geomagnetic storms.

\section{CONCLUSION}

Using data from a set of radiophysical and optical instruments, we have studied variations in different ionospheric parameters during two geomagnetic storms on April 12-15, 2016.

We have shown that these storms are classified as recurrent without sudden commencement. Solar sources of such storms are coronal holes and their associated highspeed plasma streams.

While both the storms were relatively weak, there was a pronounced ionospheric response to these disturbances. During the main phase of these storms, we observed negative disturbances of the electron density $N_{\mathrm{e}}$ and critical frequency $f_{\mathrm{o}} \mathrm{F} 2$. For the second storm, the amplitude of the negative response was higher, a decrease in $f_{\mathrm{o}} \mathrm{F} 2$ was larger than $30 \%$ relative to the quiet level. This can be explained by the fact that the second storm occurred during the recovery phase of the first one when ionospheric plasma was already disturbed. The $f_{\mathrm{o}} \mathrm{F} 2$ negative disturbance was accompanied by an increase in the $\mathrm{F} 2$ peak height. We also recorded predominantly negative plasma drift velocities in the evening and night, which differs from the characteristic behavior under quiet conditions. After the main phase of the second storm, the ion temperature rose by $200 \mathrm{~K}$ relative to the quiet day too, indicating a general increase in the thermospheric temperature. The increase in the thermospheric temperature during geomagnetic storms produces a negative response in the mid-latitude ionosphere [Klimenko et al., 2017]. During the main phase of the second storm, we also detected a peak increase in the $630 \mathrm{~nm}$ emission intensity in the atmosphere. 


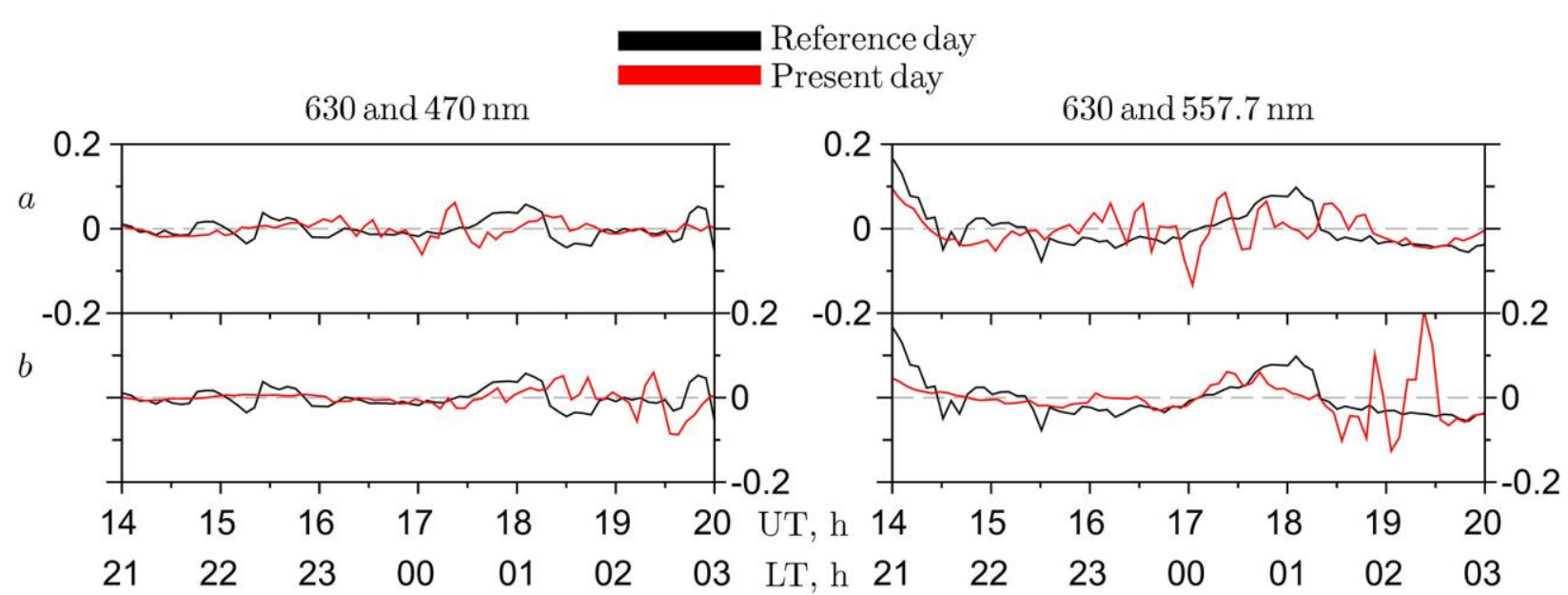

Figure 5. Airglow disturbances on April 13 (a) and April 14 (b): the ratio of difference between 630 and $557.7 \mathrm{~nm}$ (right), 630 and $470 \mathrm{~nm}$ (left) emission intensities to the $630 \mathrm{~nm}$ emission intensity (red line) against the same values on the reference day (black line)

An interesting feature of the second storm was a 1.5 -fold abrupt increase in $N_{\mathrm{e}}$ during the early main phase of the storm. This positive disturbance was observed for $\sim 7$ hours in the daytime and was accompanied by significant positive vertical plasma drift velocities, atypical for this time of day.

During the period of interest, we recorded abrupt increases in AATR and TEC noise spikes, associated with the development of small-scale irregularities. These increases had great intensity during the first storm with Fspread on ionograms but were more frequent during the second storm. On average, the percentage of noise spikes increased 2-2.5 times relative to the reference day.

We thank Yasyukevich Yu.V., Vesnin A.M., Tashlykov V.P., Vasiliev R.V., and Ratovsky K.G. for advice and assistance with data. The data on geomagnetic indices used in this paper was taken from the site of World Data Center for Geomagnetism (WDC for Geomagnetism, http://wdc.kugi.kyoto-u.ac.jp). We used data from the Unique Research Facility Irkutsk Incoherent Scatter Radar (http://ckp-rf.ru/usu/77733/). Irkutsk ionosonde data were obtained using the equipment of Center for Common Use «Angara» [http://ckp-angara.iszf.irk.ru]. $A A T R$ values were calculated using the System for the Ionosphere Monitoring and Researching from GNSS (http://simurg.iszf.irk.ru) [Yasyukevich et al., 2018]. The work was performed with budgetary funding of Basic Research program II.16 (analysis of storm dynamics, IISR data, and optical measurements) and of RF President grant No. MK-3265.2019.5 (analysis of AATR and TEC noise variations).

\section{REFERENCES}

Afraimovich E.L., Beletskii A.B., Leonovich L.A., Lesyuta O.S., Mikhalev A.V., Ashkaliev Ya.F., et al. Simultaneous radiophysical and optical measurements of the ionospheric response during the large magnetic storm of April 6, 2000. Geomagnetism and Aeronomy. 2002, vol. 42, iss. 3, pp. 366-375.

Afraimovich E.L., Voeykov S.V., Perevalova N.P., Ratovsky K.G. Large-scale traveling ionospheric disturbances of auroral origin according to the data of the GPS network and ionosondes. Adv. Space Res. 2008, vol. 42, iss. 7, pp. 12131217. DOI: 10.1016/j.asr.2007.11.023.

Afraimovich E.L., Astafyeva E.I., Demyanov V.V., Edemskiy I.K., Gavrilyuk N.S., Ishin A.B., et al. A review of GPS/GLONASS studies of the ionospheric response to natural and anthropogenic processes and phenomena. J. Space Weather and Space Climate. 2013, vol. 3, no. A27. DOI: 10.1051/ swsc/2013049.

Alsatkin S.S., Medvedev A.V., Kushnarev D.S. Analyzing the characteristics of phase-shift keyed signals applied to the measurement of an electron concentration profile using the radiophysical model of the ionosphere. Geomagnetism and Aeronomy. 2009, vol. 49, iss. 7, pp. 1022-1027. DOI: 10.1134/S0016793209070305.

Altandill D., Arrazola D., Blanch E. F-region vertical drift measurements at Ebro, Spain. Adv. Space Res. 2007, vol. 39, pp. 691-698. DOI: 10.1016/j.asr.2006.11.023.

Astafyeva E., Yasyukevich Y., Maksikov A., Zhivetiev I. Geomagnetic storms, super-storms, and their impacts on GPSbased navigation systems. Space Weather. 2014, vol. 12, iss. 7, pp. 508-525. DOI: 10.1002/2014SW001072.

Astafyeva E., Zakharenkova I., Förster M. Ionospheric response to the 2015 St. Patrick's Day storm: A global multi-instrumental overview. J. Geophys. Res.: Space Phys. 2015, vol. 120, iss. 10, pp. 9023-9037. DOI: 10.1002/2015JA021629.

Astafyeva E., Zakharenkova I., Patrick A. Prompt penetration electric fields and the extreme topside ionospheric response to the June 22-23, 2015 geomagnetic storm as seen by the Swarm constellation. Earth, Planets and Space. 2016, vol. 68, no. 152. DOI: 10.1186/s40623-016-0526-x.

Astafyeva E., Zakharenkova I., Huba J.D., Doornbos E., van den IJssel J. Global ionospheric and thermospheric effects of the June 2015 geomagnetic disturbances: Multi-instrumental observations and modeling. J. Geophys. Res.: Space Phys. 2017, vol. 122, iss. 11, pp. 11716-11742. DOI: 10.1002/2017JA024174.

Balan N., Yamamoto M., Liu J.Y., Liu H., Lühr H. New aspects of thermospheric and ionospheric storms revealed by CHAMP. J. Geophys. Res. 2011, vol. 116, no. A07305. DOI: 10.1029/2010JA016399.

Blagoveshchenskii D.V. Effect of magnetic storms (substorms) on HF propagation: A review. Geomagnetism and Aeronomy. 2013, vol. 53, iss. 4, pp. 409-423. DOI: 10.1134/ S0016793213040038.

Bryunelli B.E., Namgaladze A.A. Fizika ionosfery [Physics of the Ionosphere]. Moscow, Nauka Publ., 1988. 528 p. (In Russian). 
Buonsanto M.J. Ionospheric storms - A review. Space Science Rev. 1999, vol. 88, iss. 3, pp. 563-601, DOI: 10.1023/ A:1005107532631.

Burlaga I.P., Lepping B.P. The causes of recurrent geomagnetic storms. Planetary and Space Sci. 1977, vol. 25, iss. 12, pp. 1151-1160. DOI: 10.1016/0032-0633(77)90090-3.

Crowley G., Hackert C.L., Meier R.R., Strickland D.J., Paxton L.J., Pi X., Mannucci A., et al. Global thermosphereionosphere response to onset of 20 November 2003 storm. $J$. Geophys. Res. 2006, vol. 111, no. A10S18. DOI: 10.1029/ 2005JA011518.

Danilov A.D. Ionospheric F-region response to geomagnetic disturbances. Adv. Space Res. 2013, vol. 52, iss. 3, pp. 343-366. DOI: 10.1016/j.asr.2013.04.019.

Demyanov V.V., Yasukevich Yu.V. Mekhanizmy vozdeistviya neregulyarnykh geofizicheskikh faktorov na funktsionirovanie sputnikovykh radionavigatsionnykh system [Mechanisms of Impact of Irregular Geophysical Factors on Operation of Radio Positioning Satellite Systems]. Irkutsk, Izdatelstvo IGU, 2014. 349 p. (In Russian).

Demyanov V.V., Yasyukevich Yu.V., Jin S., Sergeeva M.A. The second-order derivative of GPS carrier phase as a promising means for ionospheric scintillation research. Pure and Applied Geophys. July 2019, pp. 1-19. DOI: 10.1007/ s00024-019-02281-6.

Dow J.M., Neilan R.E., Rizos C. The International GNSS Service in a changing landscape of Global Navigation Satellite Systems. J. Geodesy. 2009, vol. 83, iss. 3-4, pp. 191-198. DOI: 10.1007/s00190-008-0300-3.

Fuller-Rowell T.J., Codrescu M.V., Rishbeth H., Moffett R.J., Quegan S. On the seasonal response of the thermosphere and ionosphere to geomagnetic storms. J. Geophys. Res. 1996, vol. 101, iss. A2, pp. 2343-2353. DOI: 10.1029/95JA01614.

Juan J.M., Sanz J., Rovira-Garcia A., González-Casado G., Ibáñez D., Perez R.O. AATR an ionospheric activity indicator specifically based on GNSS measurements. J. Space Weather and Space Climate. 2018, vol. 8, no. A14. DOI: 10.1051/ swsc/2017044.

Klimenko M.V., Klimenko V.V., Zakharenkova I.E., Ratovsky K.G., Korenkova N.A., Yasyukevich Yu.V., Mylnikova A.A., Cherniak Yu.V. Similarity and differences in morphology and mechanisms of the foF2 and TEC disturbances during the geomagnetic storms on 26-30 September 2011. Ann. Geophysicae. 2017, vol. 35, iss. 4, pp. 923-938. DOI: 10.5194/angeo35-923-2017.

Klimenko M.V., Klimenko V.V., Despirak I.V., Zakharenkova I.E., Kozelov B.V., Cherniakov S.M., et al. Disturbances of the thermosphere - ionosphere - plasmasphere system and auroral electrojet at $30^{\circ} \mathrm{E}$ longitude during the St. Patrick's Day geomagnetic storm on 17-23 March 2015. J. Atm. SolarTerr. Phys. 2018, vol. 180, pp. 78-92. DOI: 10.1016/ j.jastp.2017.12.017.

Kotova D.S., Klimenko M.V., Klimenko V.V., Zakharov V.E. Influence of geomagnetic storms of September 26-30, 2011, on the ionosphere and HF radiowave propagation. II. Radiowave propagation. Geomagnetism and Aeronomy. 2017, vol. 57, iss. 3, pp. 288-300. DOI: 10.1134/S0016793217030100.

Kurkin V.I., Polekh N.M., Pirog O.M., Chistyakova L.V., Zherebtsov G.A. The solar wind magnetic cloud of October, 18-20, 1995 effect on ionosphere of the Russian Asian region. Adv. Space Res. 2001, vol. 27, iss. 8, pp. 1381-1384. DOI: 10.1016/S0273-1177(01)00041-2.

Kurkin V.I., Pirog O.M., Polekh N.M. Cyclic and seasonal variations in the ionospheric effects of geomagnetic storms. $G e-$ omagnetism and Aeronomy. 2004, vol. 44, iss. 5, pp. 583-591.

Kurkin V.I., Polekh N.M., Zolotukhina N.A. The pattern of ionospheric disturbances caused by complex interplanetary structure on 19-22 December 2015. J. Atm. Solar-Terr. Phys. 2018, vol. 179, pp. 472-483. DOI: 10.1016/j.jastp.2018.07.003.

Leonovich L.A., Mikhalev A.V., Leonovich V.A. Manifestation of geomagnetic disturbances in mid-latitude upper atmosphere glow. Solnechno-zemnaya fizika [Solar-Terr. Phys.]. 2012, iss. 20, pp. 109-115. (In Russian).

Leonovich L.A., Mikhalev A.V., Tashchilin A.V., Rahmatulin R.A., Leonovich V.A., Pashinin A.Yu. The response of mid-latitude upper atmospheric parameters to January 21, 2005 geomagnetic storm as deduced from optical, magnetic and radiophysical measurements. Optika atmosfery $i$ okeana [Atmospheric and Oceanic Optics]. 2013, vol. 26, iss. 1, pp. 75-80. (In Russian).

Loewe C.A., Prölss G.W. Classification and mean behavior of magnetic storms. J. Geophys. Res. 1997, vol. 102, iss. A7, pp. 14209-14213. DOI: 10.1029/96JA04020.

Mendillo M. Storms in the ionosphere: patterns and processes for total electron content. Rev. Geophys. 2006, vol. 44, RG4001. DOI: 10.1029/2005RG000193.

Mikhalev A.V. Midlatitude airglows in East Siberia in 1991-2012. Solnechno-zemnaya fizika [Solar-Terr. Phys.]. 2013, iss. 24, pp. 78-83. (In Russian).

Pi X., Mannucci A.J., Lindqwister U.J., Ho C.M. Monitoring of global ionospheric irregularities using the Worldwide GPS Network. Geophysical Res. Lett. 1997, vol. 24, iss. 18, pp. 2283-2286. DOI: 10.1029/97GL02273.

Piggott W.R., Rawer K. U.R.S.I. Handbook of Ionogram Interpretation and Reduction. $2^{\text {nd }}$ ed. Report UAG-23, WDC-A for STP, NOAA, Boulder, Colorado, 1972. 135 p.

Polekh N., Zolotukhina N., Kurkin V., Zherebtsov G., Shi J., Wang G., Wang Z. Dynamics of ionospheric disturbances during the 17-19 March 2015 geomagnetic storm over East Asia. Adv. Space Res. 2017, vol. 60, iss. 11, pp. 2464-2476. DOI: 10.1016/j.asr.2017.09.030.

Potekhin A.P., Medvedev A.V., Zavorin A.V., Kushnarev D.S., Lebedev V.P., Lepetaev V.V., Shpynev B.G. Recording and control digital systems of the Irkutsk Incoherent Scattering Radar. Geomagnetism and Aeronomy. 2009, vol. 49, iss. 7, pp. 1011-1021. DOI: 10.1134/S0016793209070299.

Ratovsky K.G., Klimenko M.V., Klimenko V.V., Chirik N.V., Korenkova N.A., Kotova D.S. After-effects of geomagnetic storms: statistical analysis and theoretical explanation. Solar-Terr. Phys. 2018, vol. 4, iss. 4, pp. 26-32. DOI: 10.12737/ stp-44201804.

Reinisch B.W., Haines D.M., Bibl K., Galkin I.A., Huang X., Kitrosser D.F., Sales G.S., Scali J.L. Ionospheric sounding in support of over-the-horizon radar. Radio Sci. 1997, vol. 32, iss. 4, pp. 1681-1694. DOI: 10.1029/97RS00841.

Rodger A.S., Wrenn G.L., Rishbeth H. Geomagnetic storms in the Antarctic F-region. II. Physical interpretation. J. Atm. Terr. Phys. 1989, vol. 51, iss. 11-12, pp. 851-866. DOI: 10.1016/0021-9169(89)90002-0.

Romanova E.B., Zherebtsov G.A., Ratovsky K.G., Polekh N.M., Shi J., Wang X., Wang G. Comparing the ionosphere F2layer response to geomagnetic storms at mid and low latitudes. Solnechno-zemnaya fizika [Solar-Terr. Phys.]. 2013, iss. 22, pp. 27-30. (In Russian).

Sanz J., Juan J.M., Hernández-Pajares M. GNSS data processing. Vol. 1: Fundamentals and Algorithms. Noordwijk, ESA communications, 2013. 223 p.

Shcherbakov A.A., Medvedev A.V., Kushnarev D.S., Tolstikov M.V., Alsatkin S.S. Calculation of meridional neutral winds in the middle latitudes from the Irkutsk Incoherent Scatter Radar. J. Geophys. Res. Space Phys. 2015, vol. 120, iss. 12, pp. 10851-10863. DOI: 10.1002/2015JA021678.

Tashchilin A.V., Leonovich L.A. Modeling nightglow in atomic oxygen red and green lines under moderate disturbed geomagnetic conditions at midlatitudes. Solar-Terr. Phys. 2016, vol. 2, iss. 4, pp. 94-106. DOI: 10.12737/24276. 
Tashlykov V.P., Medvedev A.V., Vasilyev R.V. Backscatter signal model for Irkutsk Incoherent Scatter Radar. SolarTerr. Phys. 2018, vol. 4, iss. 2, pp. 24-32. DOI: 10.12737/stp42201805.

Wrenn G.L., Rodger A.S., Rishbeth H. Geomagnetic storms in the Antarctic F-region. 1. Diurnal and seasonal patterns for main phase effects. J. Atm. Terr. Phys. 1987, vol. 49, iss. 9, pp. 901-913. DOI: 10.1016/0021-9169(87)90004-3.

Yasyukevich Yu.V., Zhivetiev I.V., Kiselev A.V., Edemskiy I.K., Syrovatsky S.V., Shabalin A.S., Vesnin A.M. Tool for creating maps of GNSS total electron content variations. Proc. 2018 Symposium "Progress In Electromagnetics Research”. Toyama, Japan, 1-4 August 2018, pp. 2417-2421. DOI: 10.23919/PIERS.2018.8597604.

Yermolaev Yu.I., Yermolaev M.Yu. Statistic study on the geomagnetic storm effectiveness of solar and interplanetary events. Adv. Space Res. 2006, vol. 37, iss. 6, pp. 1175-1181. DOI: 10.1016/j.asr.2005.03.130.

Zherebtsov G.A., Zavorin A.V., Medvedev A.V., Nosov V.E., Potekhin A.P., Shpynev B.G. The Irkutsk Incoherent Scattering Radar. J. Communications Technology and Electronics. 2002, vol. 47, iss. 11, pp. 1222-1228.

Zolotukhina N.A., Kurkin V.I., Polekh N.M. Ionospheric disturbances over East Asia during intense December magnetic storms of 2006 and 2015: similarities and differences. SolarTerr. Phys. 2018, vol. 4, iss. 3, pp. 28-42. DOI: $10.12737 /$ stp43201805.

URL: http://wdc.kugi.kyoto-u.ac.jp/qddays/index.html (accessed January 20, 2020).

How to cite this article

Rubtsov A.V., Maletckii B.M., Danilchuk E.I., Smotrova E.E., Shelkov A.D., Yasyukevich A.S. Ionospheric disturbances over Eastern Siberia during April 12-15, 2016 geomagnetic storms. Solar-Terrestria Physics. 2020. Vol. 6. Iss 1. P. 60-68. DOI: 10.12737/stp-61202007. 